\title{
Transient Loss of Consciousness; Syncope or Seizure: A Case Report
}

\section{Zahra Parsaei Mehr ${ }^{1}$, Zohreh Mohamadzadeh Tabrizi ${ }^{2}$, Ali Tajabadi ${ }^{3}$, Zohre Saghi ${ }^{1}$, Saeed Ghalenovi ${ }^{4}$ \\ ${ }^{1}$ Department of Nursing, School of Nursing and Midwifery, Sabzevar University of Medical Sciences, Sabzevar, Iran ${ }^{2}$ Faculty of Paramedical, Sabzevar University of Medical Sciences, Sabzevar, Iran \\ ${ }^{3}$ Department of Medical Urgency, Faculty of Paramedical, Sabzevar University of Medical Sciences, Sabzevar, Iran ${ }^{4}$ Faculty of Medicine, Sabzevar University of Medical Sciences, Sabzevar, Iran}

\section{A BSTRACT}

Introduction: Transient loss of consciousness (TLOC) is one of the common causes for referral to hospital. Syncope and seizure can cause TLOC. Syncope and seizures can be the consequences of each other's. Their common features often lead to misdiagnosis. Case Description: The purpose of this study was to present a patient (male, over 80 years), who received antiepileptic treatment for 6 years for seizure-related transient loss of consciousness. Results: Due to repeated episodes of suspected syncope, insertion of a dual-chamber PPM was done. After three years of follow-up, he did not report the occurence of the TLOC. Conclusion: The frequency of the TLOC and its complications emphasize the importance of proper assessments, diagnosis, and treatment. A comprehensive history taking, exact examination, and para-clinical assessments can be very helpful for diagnosis. An incorrect diagnosis can cause economic, psychological, and social problems.

*Corresponding Author: Zohreh Mohamadzadeh Tabrizi

E-mail: mohamadzadehtz1@gmail.com 


\section{كاهش كَراى هوشيارى: سنكوٍ يا تشنج: گزارش يك مورد}

زهرا يارسائى مهر'، زهره محمدزاده تبريزى Гّ"، على تاجآبادى"، زهره ساقى'، سعيد قلعه نويى'

$$
\begin{aligned}
& \text { كروه يرستارى، دانشكده يرستارى و مامايى، دانشكاه علوم يزشكى سبزوار، سبزوار، ايران } \\
& \text { 'دانشكده يِيرايزشكى، دانشعاه علوم يزشكى سبزوار، سبزوار، ايران } \\
& \text { "كروه فوريت يزشكى، دانشكده بيرايزشكى، دانشكاه علوم يزشكى سبزوار، سبزوار، ايران } \\
& \text { "دانشكده يزشكى، دانشكاه علوم يزشكى سبزوار، سبزوار، ايران }
\end{aligned}
$$

\section{اطلاعات مقاله:}

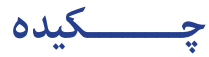

مقدمه: حملات كاهش كذراى هوشيارى يكى از علل شايع مراجعه به بيمارستان است. سنكوب و

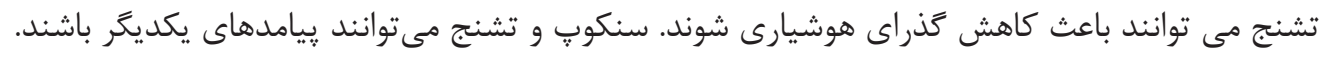

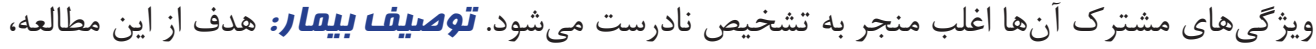
ارائٔ يك بيمار (مرد، بالاى هشتاد سال) بود كه به مدت

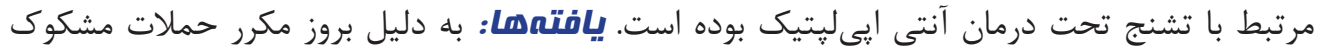

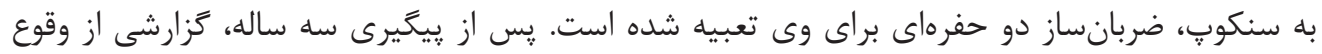

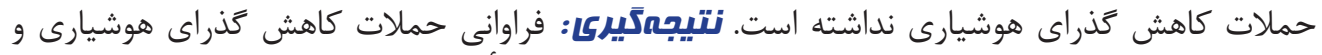

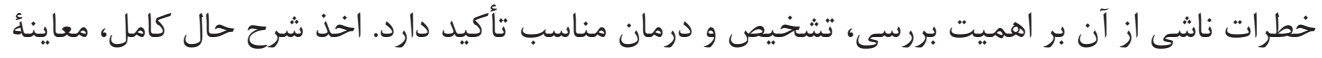

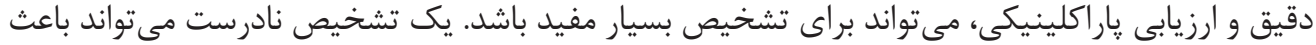
مشكلات اقتصادى، روانى و اجتماعى شود.

كليد وازمها:

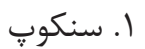

r.

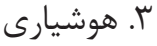

" نويسنده مسئول: زهره محمدزاده تبريزى آدرس الكترونيكى: mohamadzadehtz1@gmail.com 


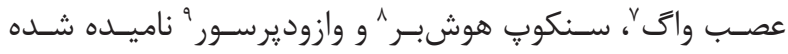

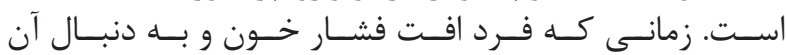

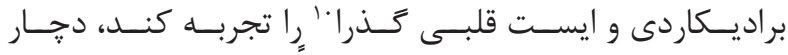

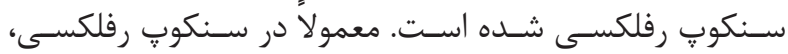

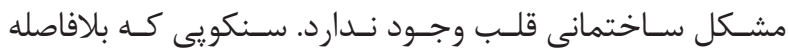

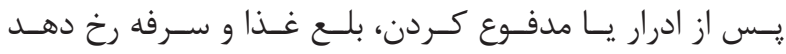

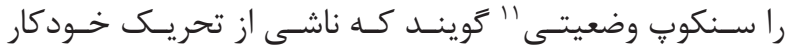

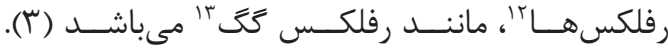

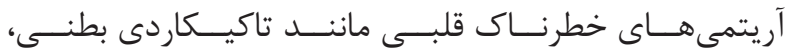

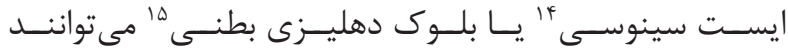

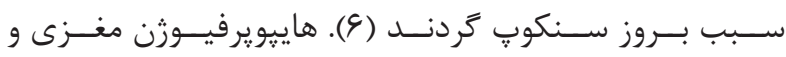

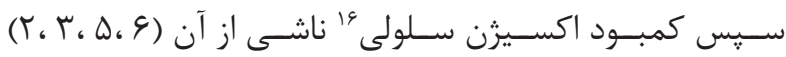

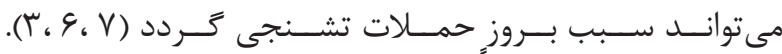

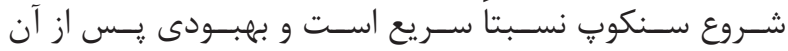

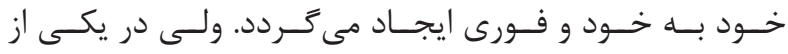

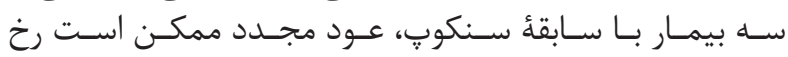

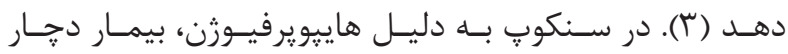

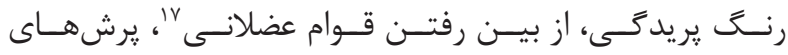

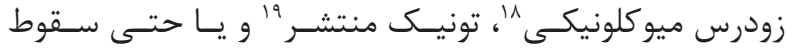

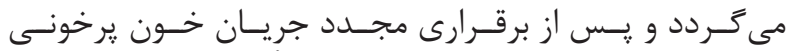

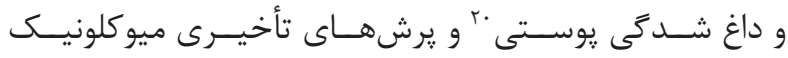

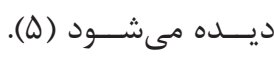

\section{توصيف بيمار}

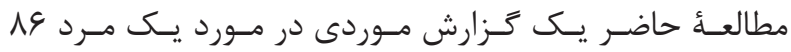

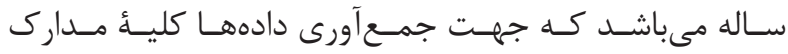

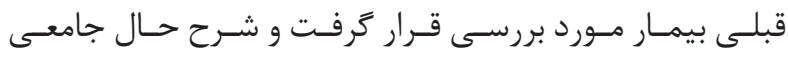

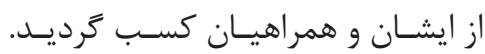

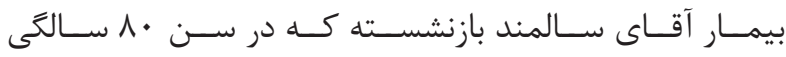

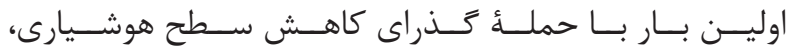

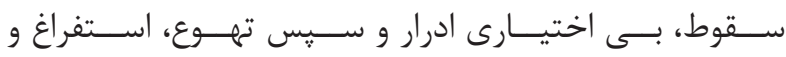

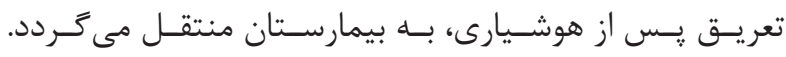

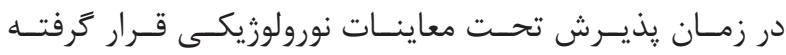

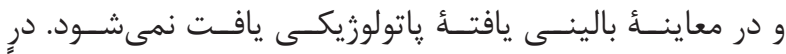

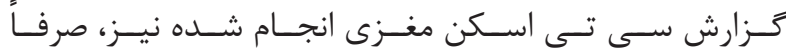

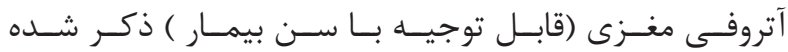

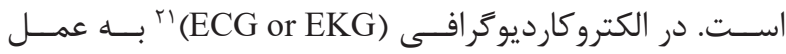

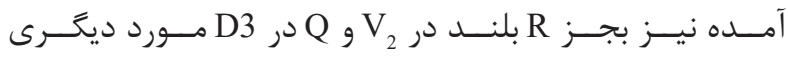

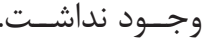

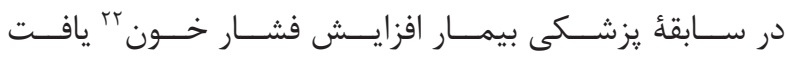

${ }^{1}$ Transient loss of consciousness

${ }^{2}$ Cerebral hypo perfusion

${ }^{3}$ Bradycardia-tachycardia

${ }^{4}$ Orthostatic hypotention

${ }^{5}$ Reflex syncope

${ }^{6}$ Neurally mediated syncope

${ }^{7}$ Vasovagal syncope

${ }^{8}$ Neurocardiogenic syncope

${ }^{9}$ Vasodepressor syncope

${ }^{10}$ Transient asystole

${ }^{11}$ Situational syncope

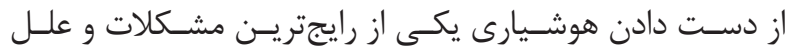

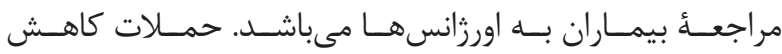

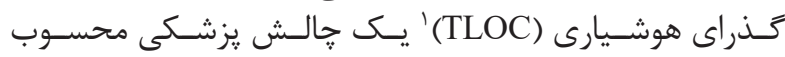

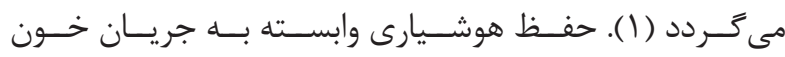

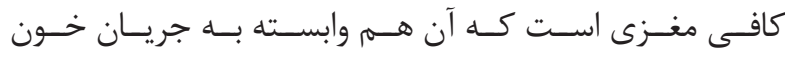

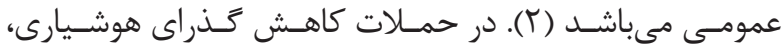

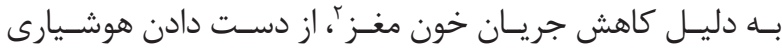

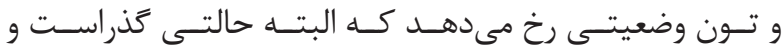

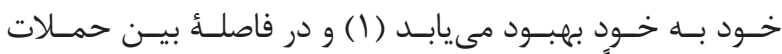

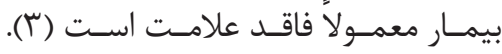

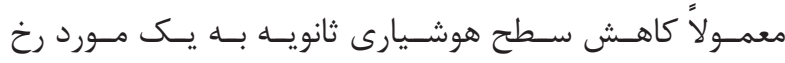

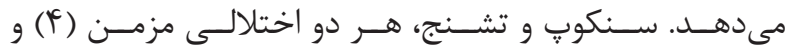

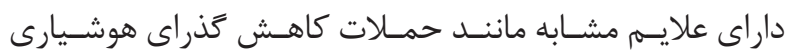

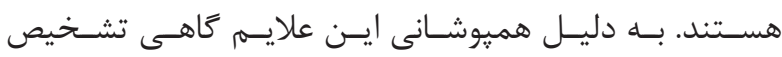

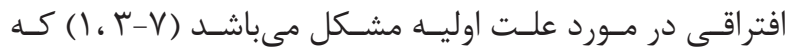

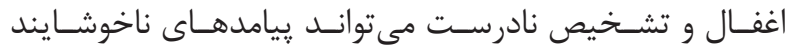

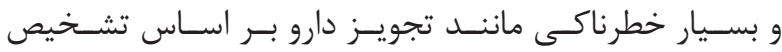

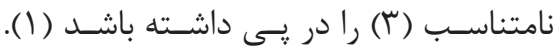

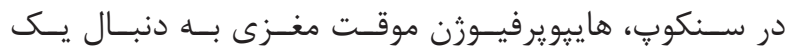

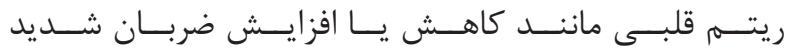

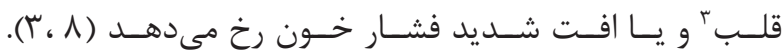

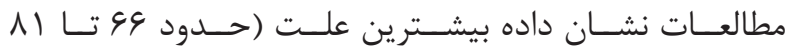

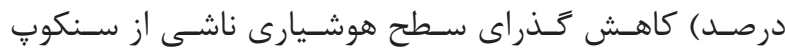

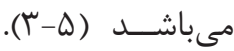

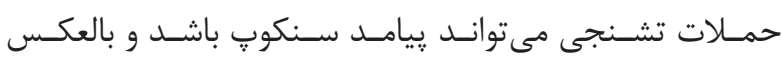

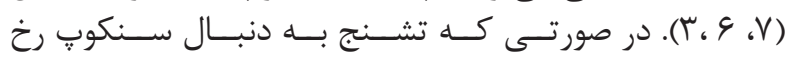

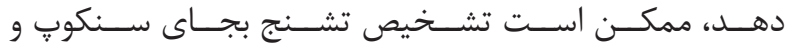

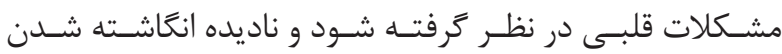

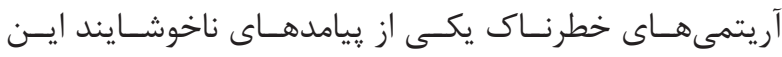

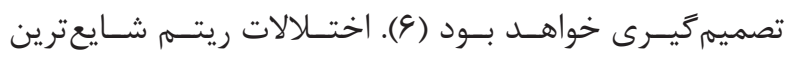

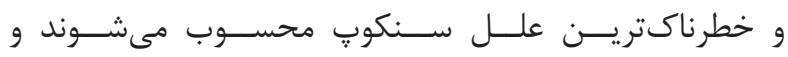

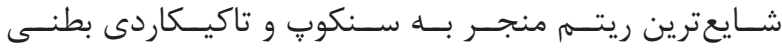

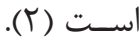

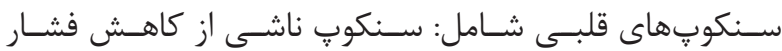

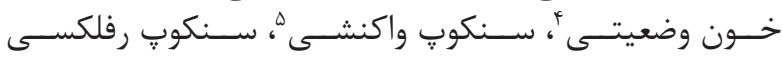

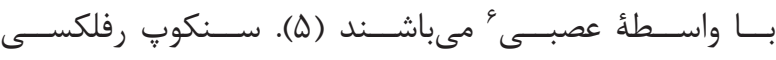

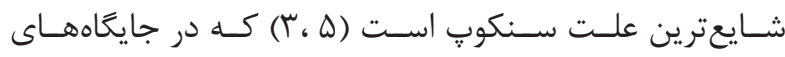

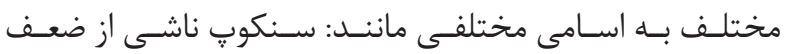

${ }^{12}$ Autonomic reflexes

${ }^{13} \mathrm{Gag}$ reflex

${ }^{14}$ Sinus arrest

${ }^{15}$ Atrioventricular block

${ }^{16}$ Anoxia

${ }^{17}$ Atonia

${ }^{18}$ Early myoclonic jerks

${ }^{19}$ Generalized tonic

${ }^{20}$ Skin flushing

${ }^{21}$ Electrocardiogram

${ }^{22}$ Hypertension 


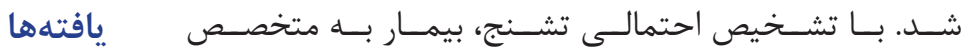

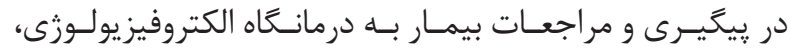

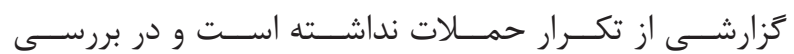

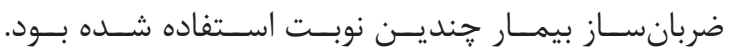

\section{بحث و نتيجه كيرى}

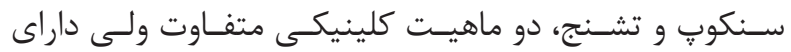

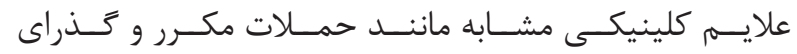

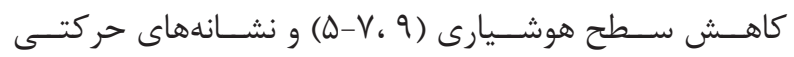

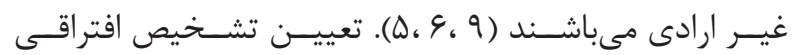

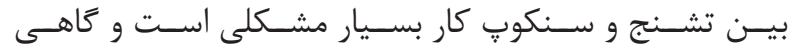

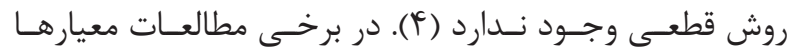

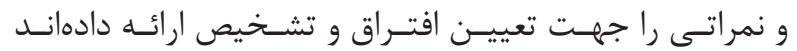

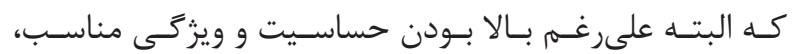

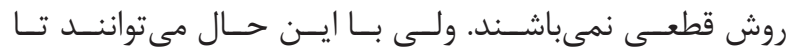

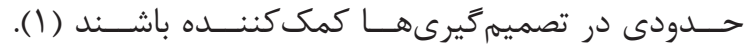

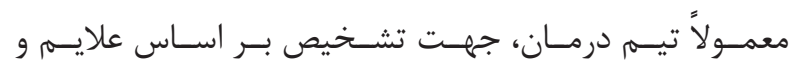

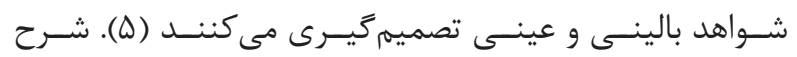

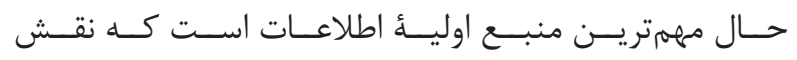

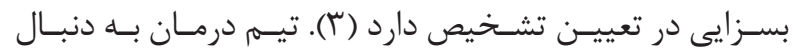

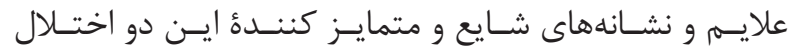

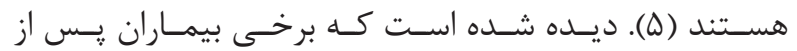

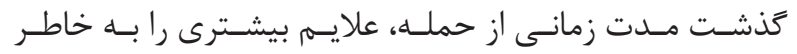

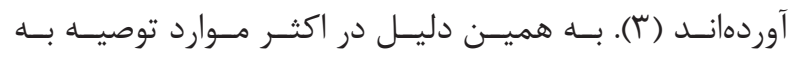

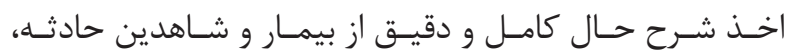

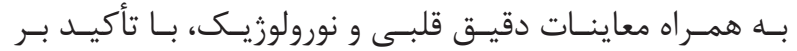

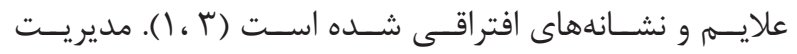

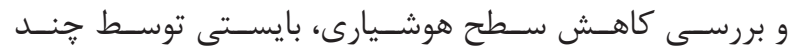

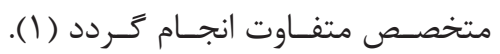

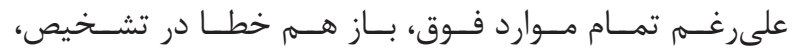

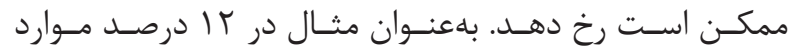

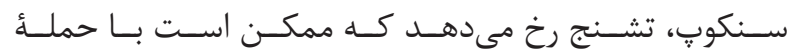

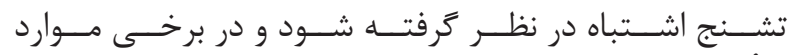

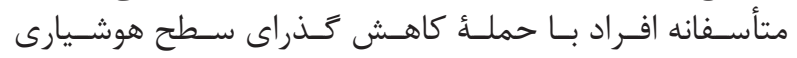

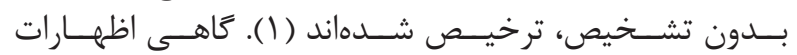

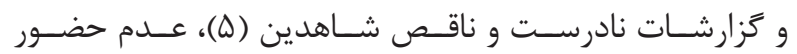

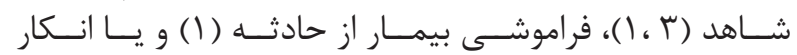

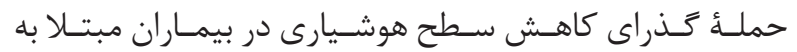

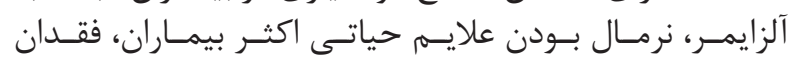

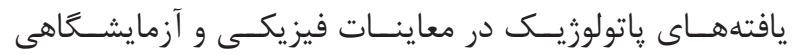

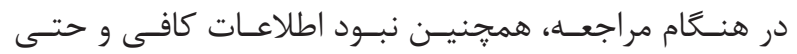

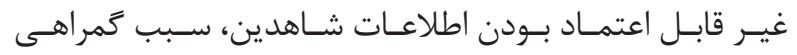

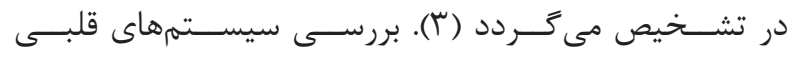

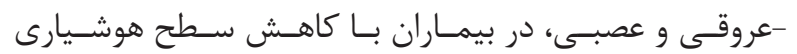

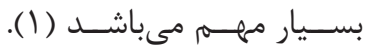

${ }^{23}$ Carotid artery

${ }^{24}$ Diaforesis

${ }^{25}$ Echocardiography

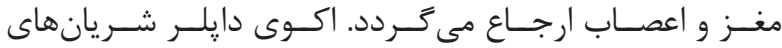

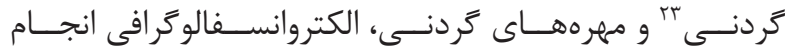

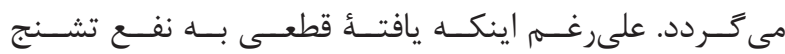

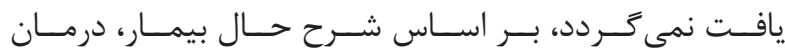

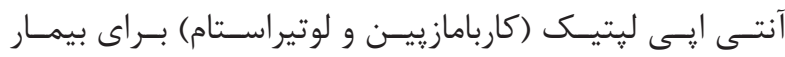

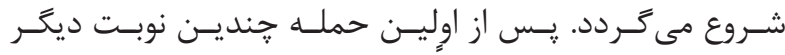

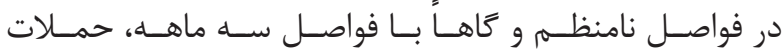

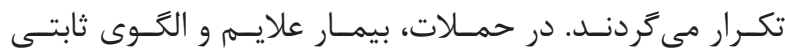

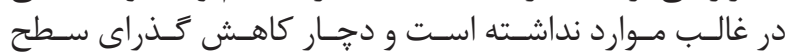

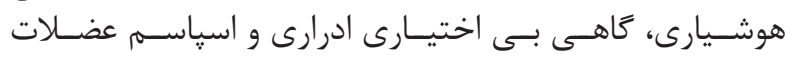

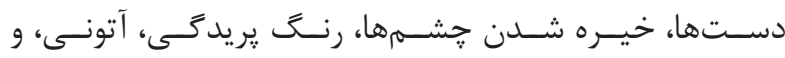

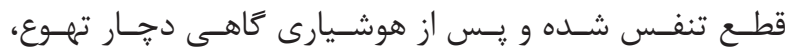

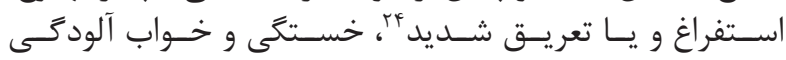

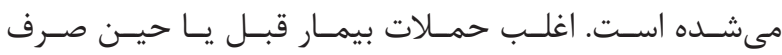

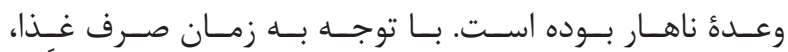

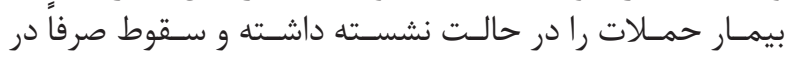

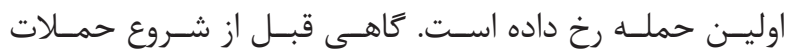

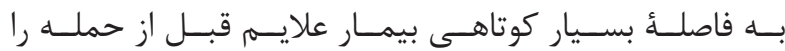

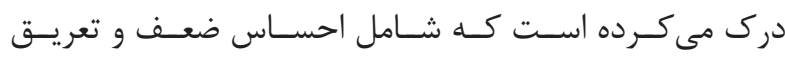

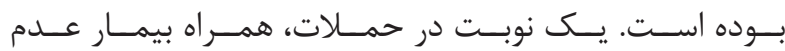

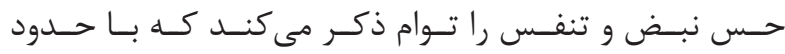

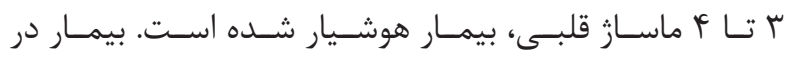

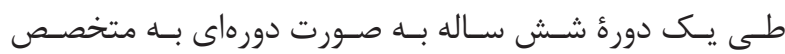

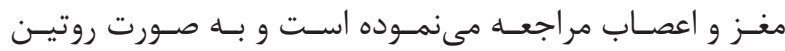

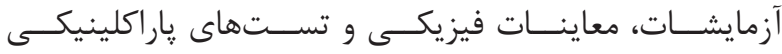

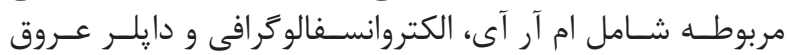

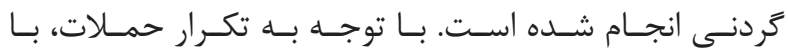

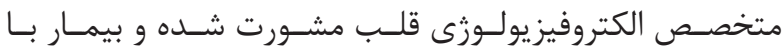

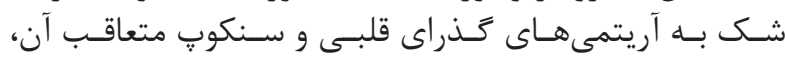

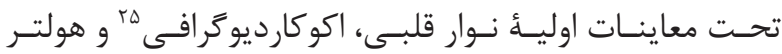

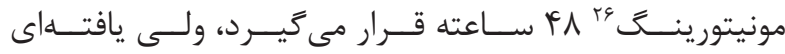

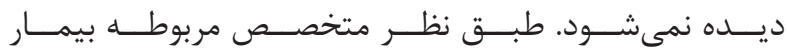

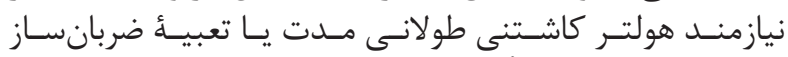

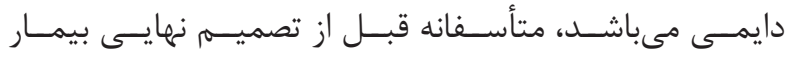

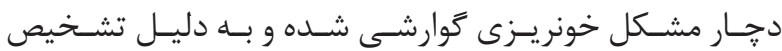

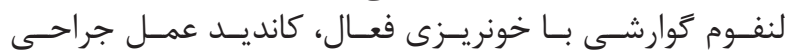

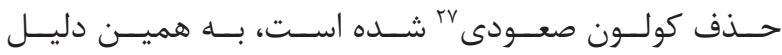

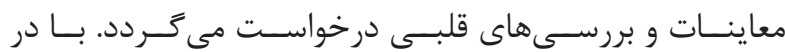

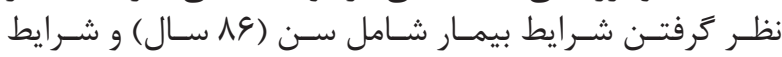

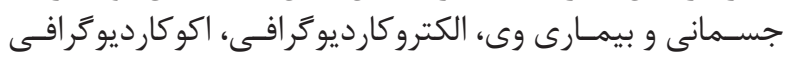

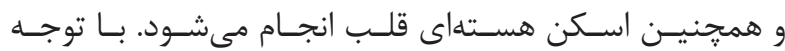

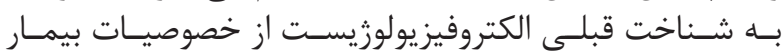

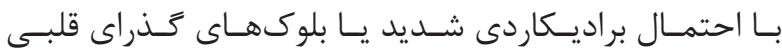

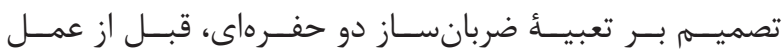

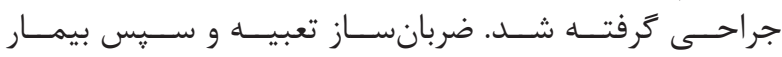

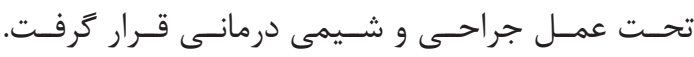

${ }^{26}$ Holter monitor

${ }^{27}$ Hemicolectomy 


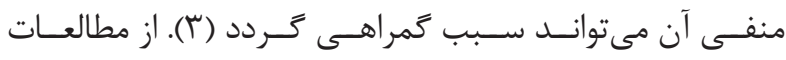

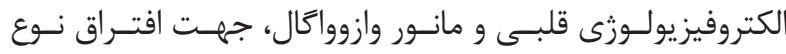

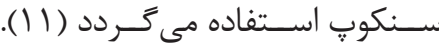

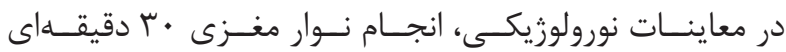

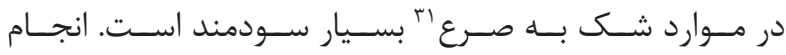

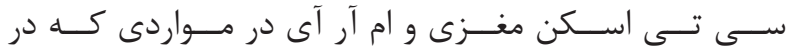

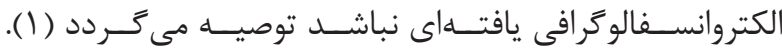

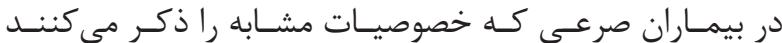

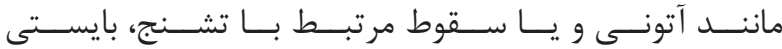

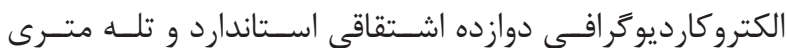

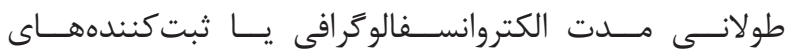

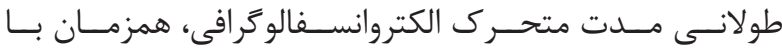

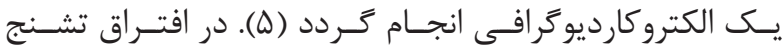

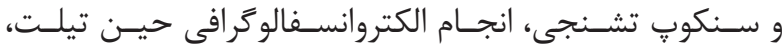

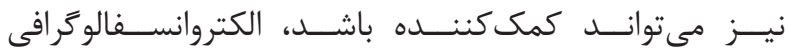

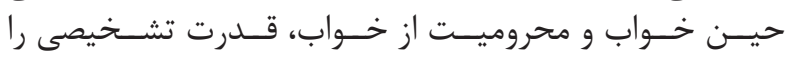

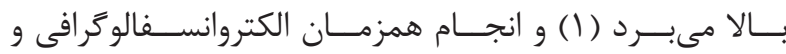

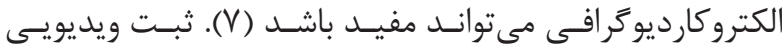

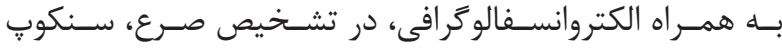

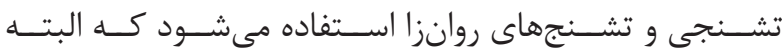

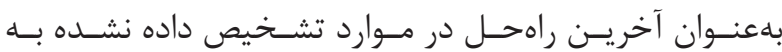

كار مسرود (1) - (1)

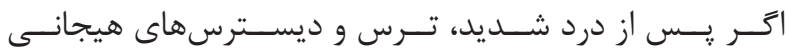

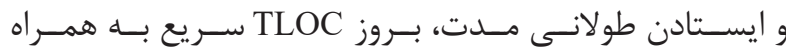

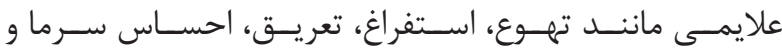

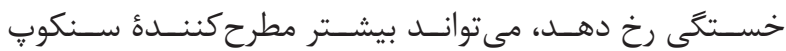

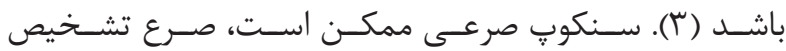

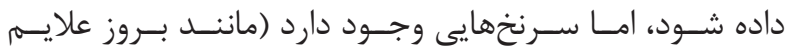

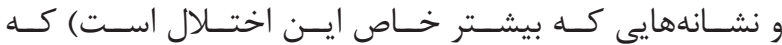

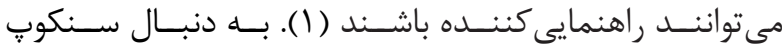

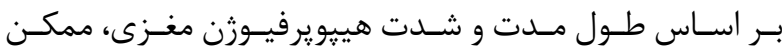

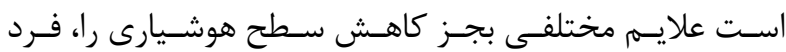

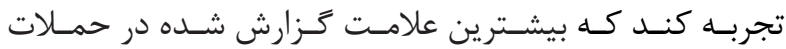

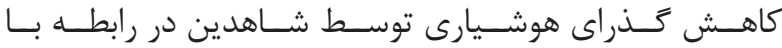

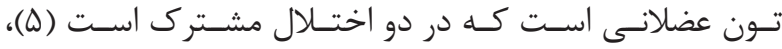

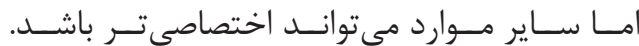

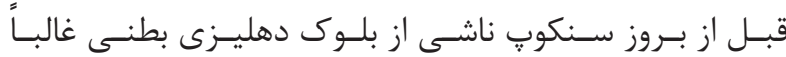

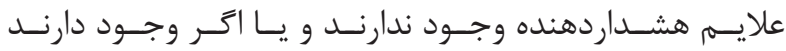

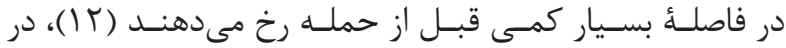

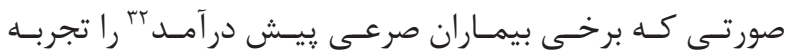

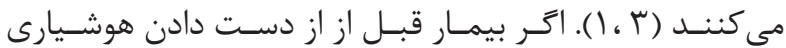

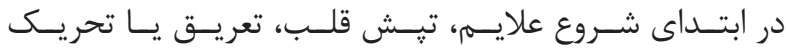

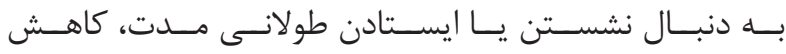

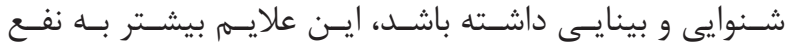

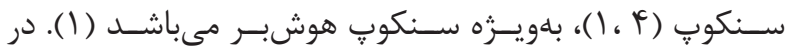

${ }^{28}$ Electrophysiological disorders of the heart

${ }^{29}$ Cardiogenic syncope

${ }^{30}$ Bruit

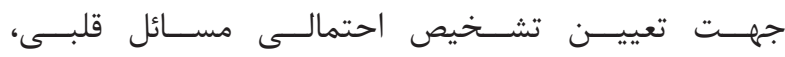

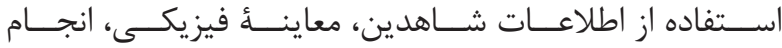

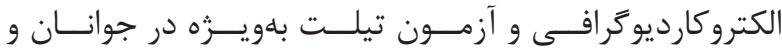

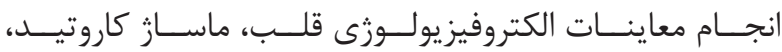

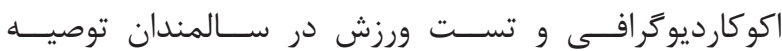

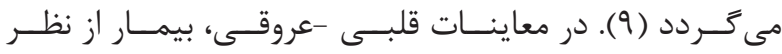

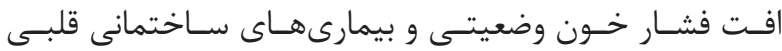

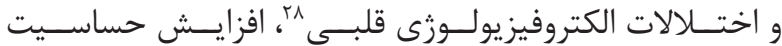

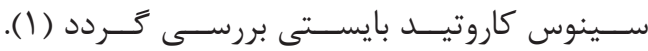

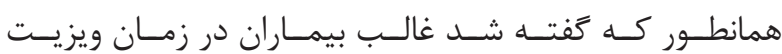

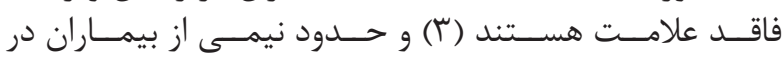

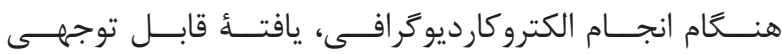

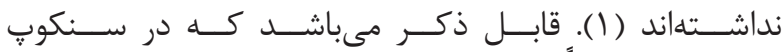

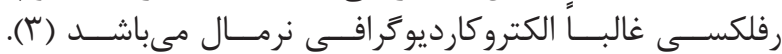

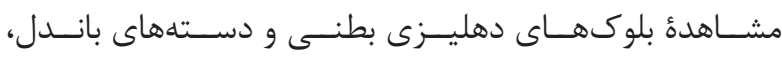

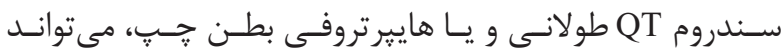

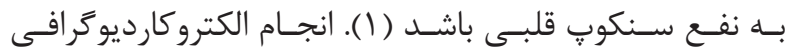

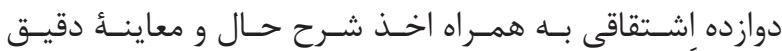

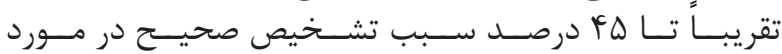

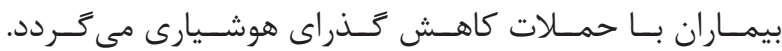

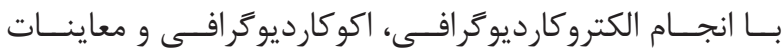

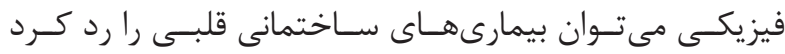

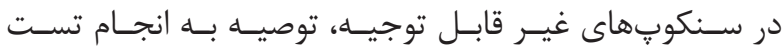

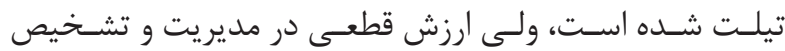

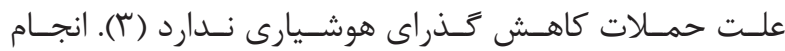

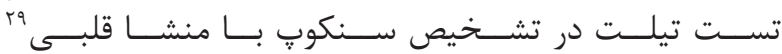

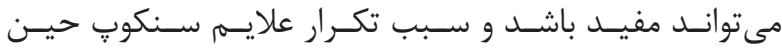

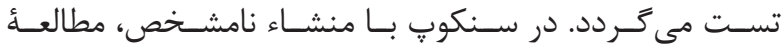

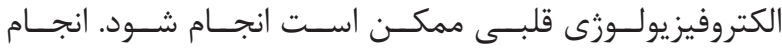

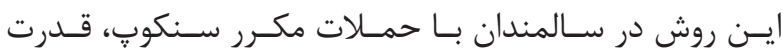

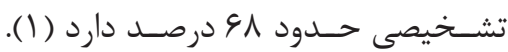

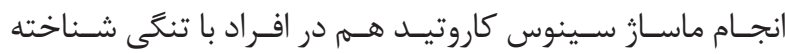

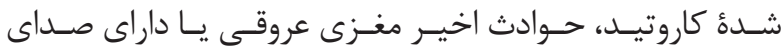

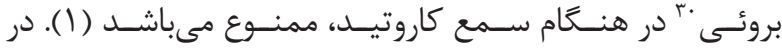

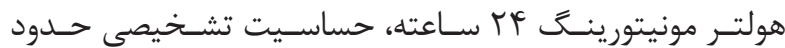

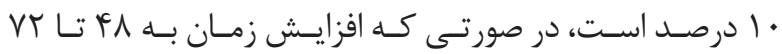

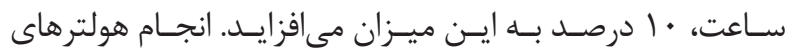

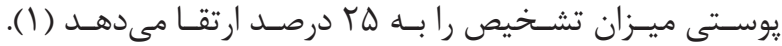

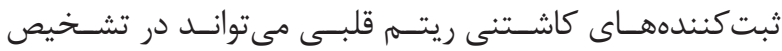

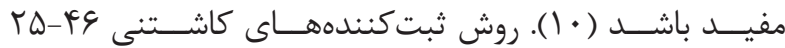

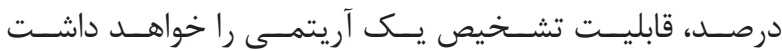

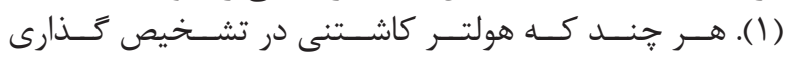

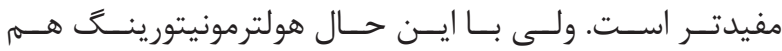

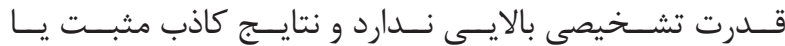




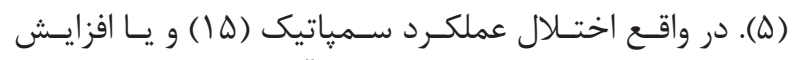

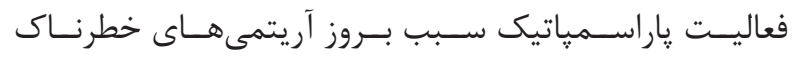

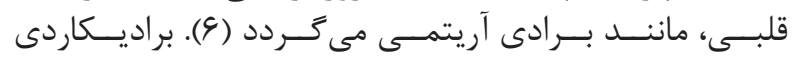

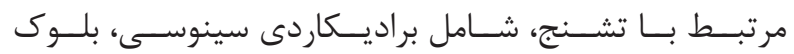

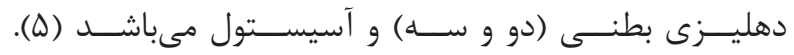

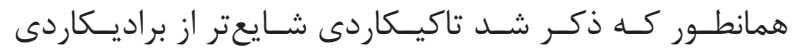

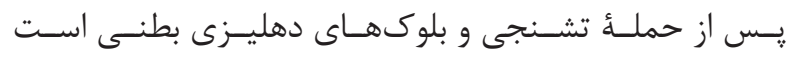

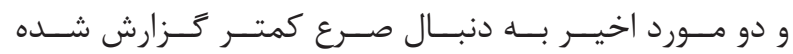

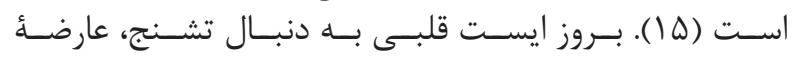

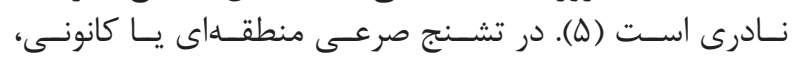

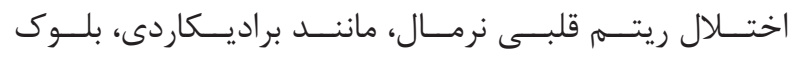

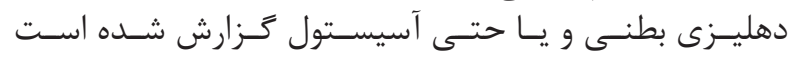

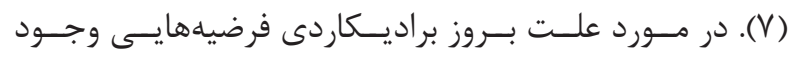

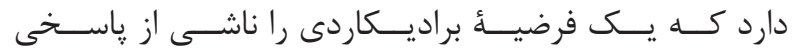

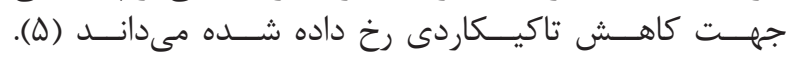

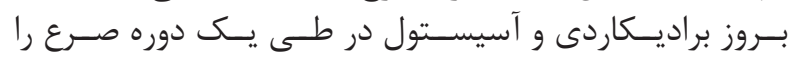

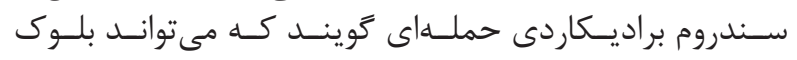

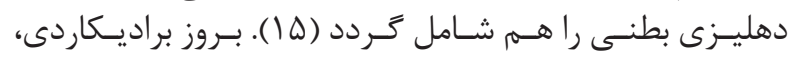

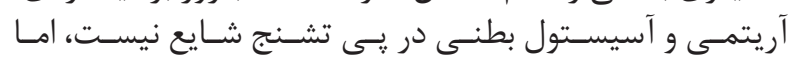

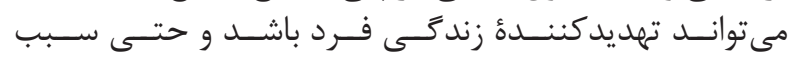

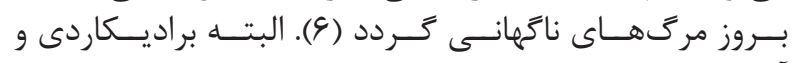

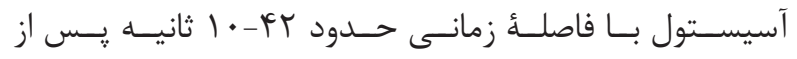

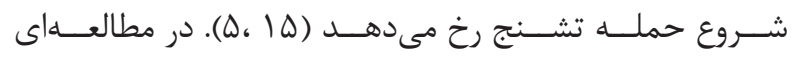

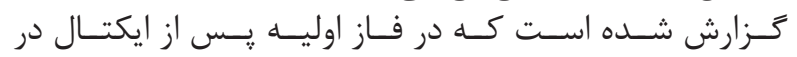

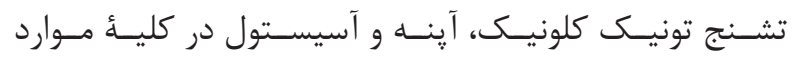

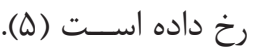

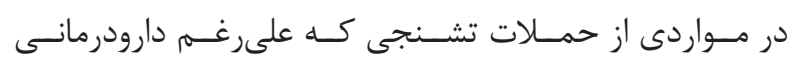

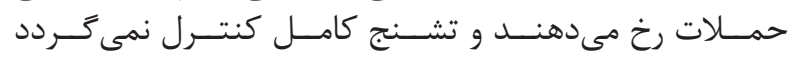

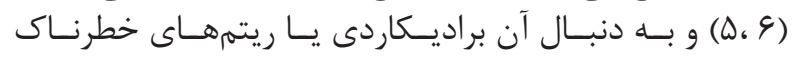

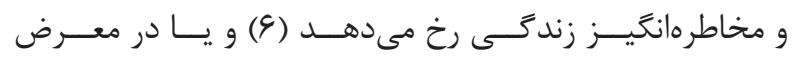

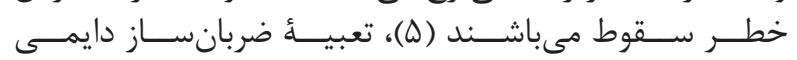

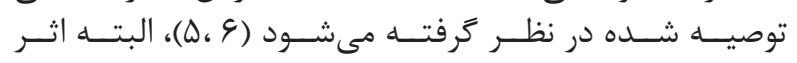

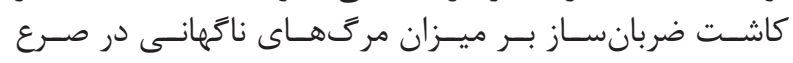

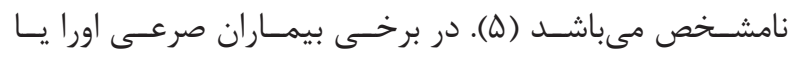

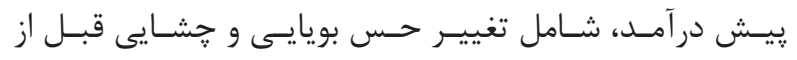

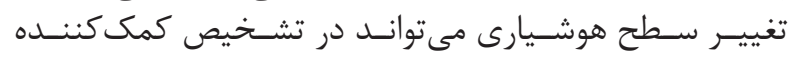

باشـد (广).

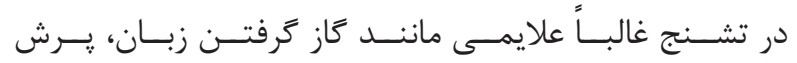

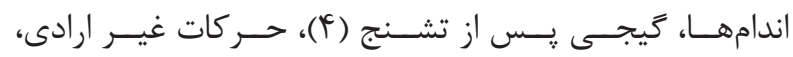

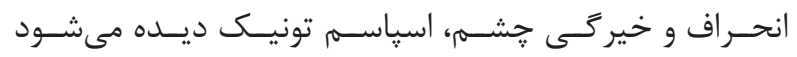

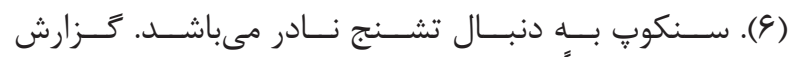

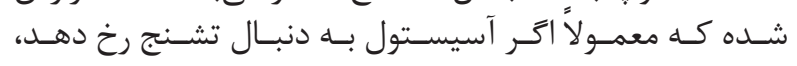

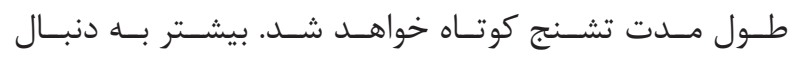

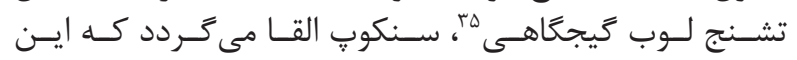

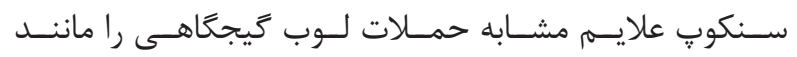

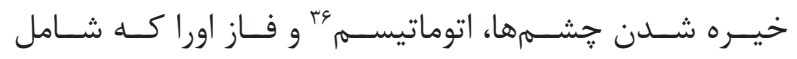

${ }^{33}$ Hypertrophic cardiomyopathy

${ }^{34}$ Tachypnea

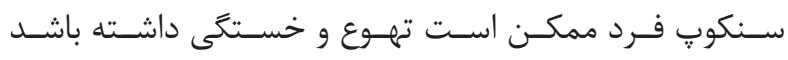

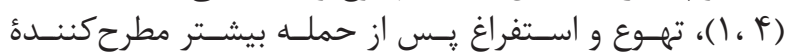

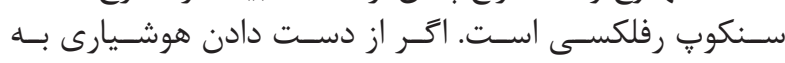

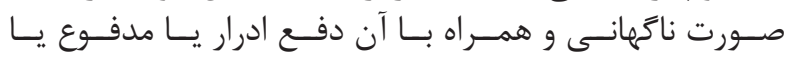

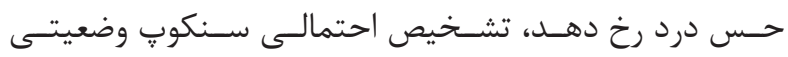

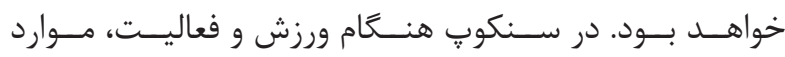

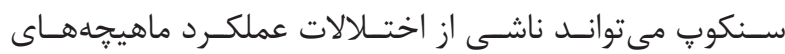

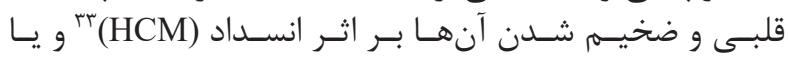

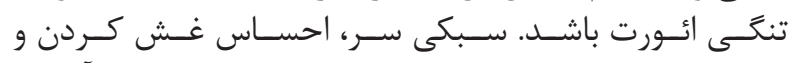

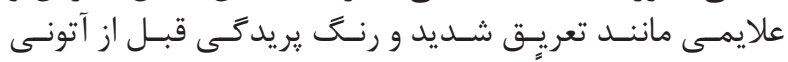

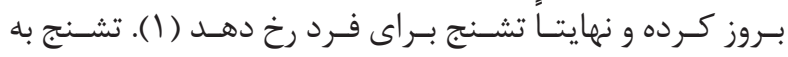

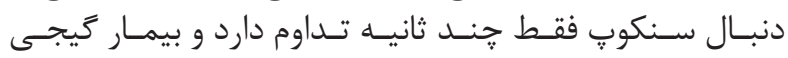

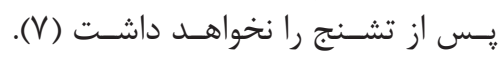

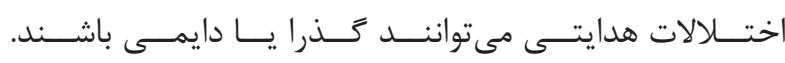

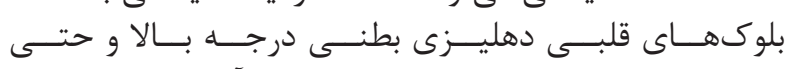

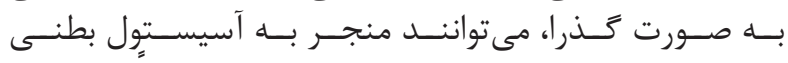

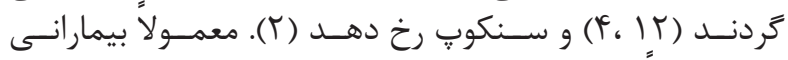

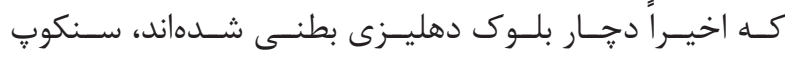

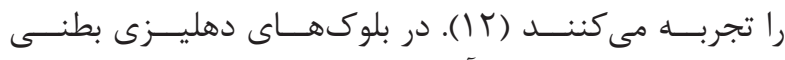

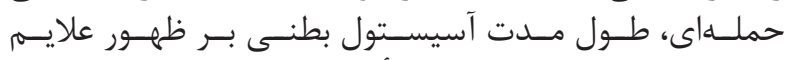

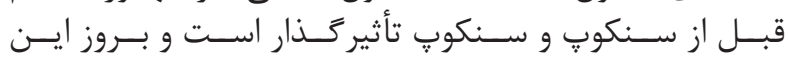

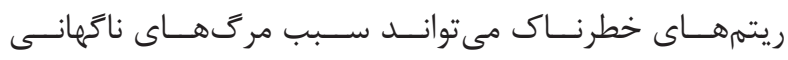

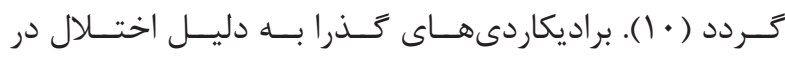

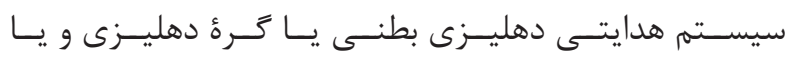

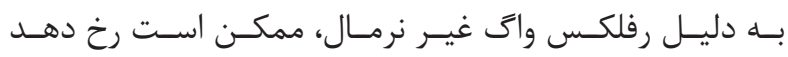

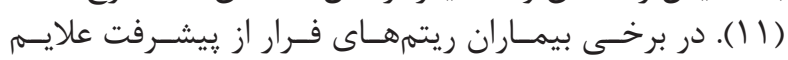

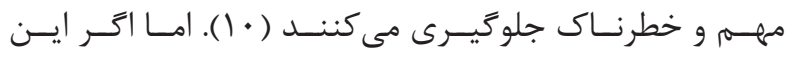

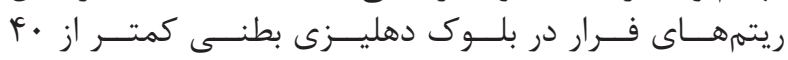

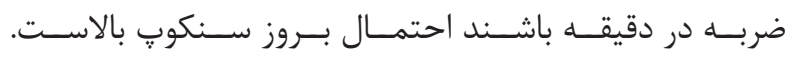

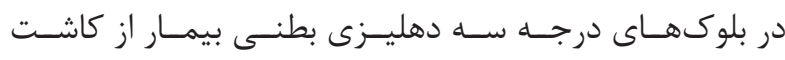

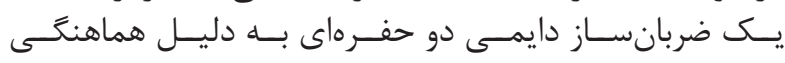

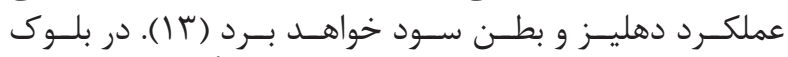

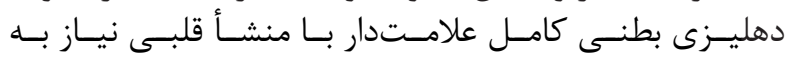

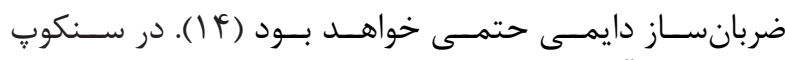

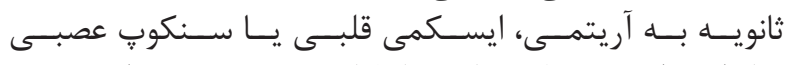

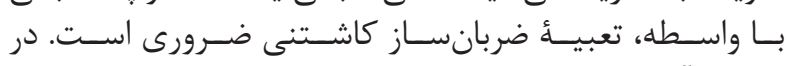

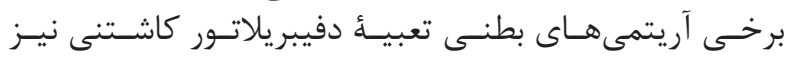

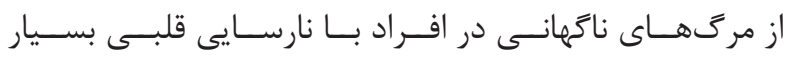

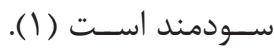

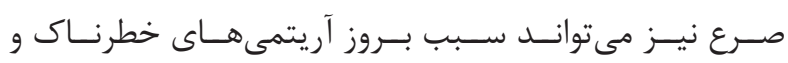

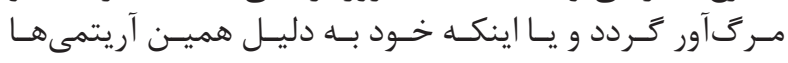

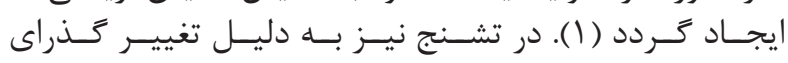

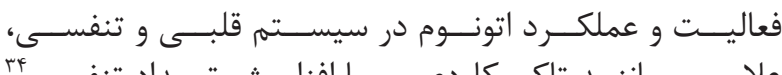

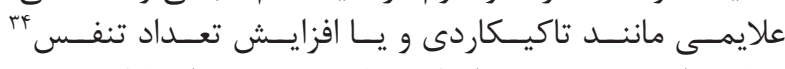

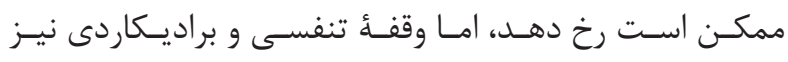

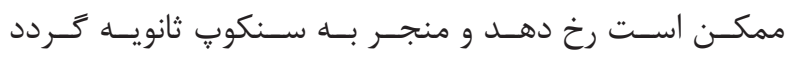

${ }^{35}$ Temporal lobe

${ }^{36}$ Automatisms 


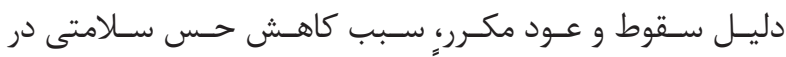

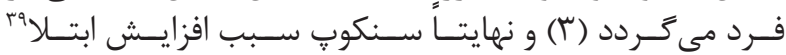

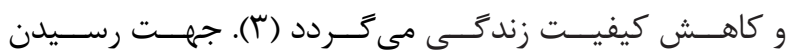

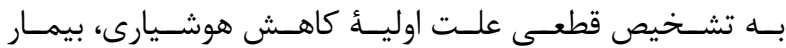

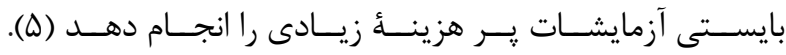

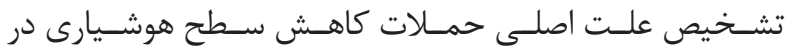

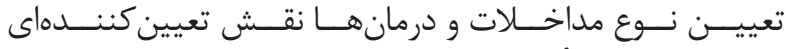

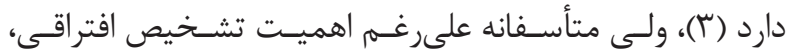

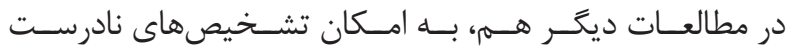

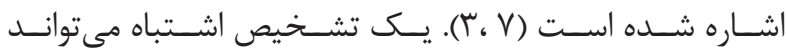

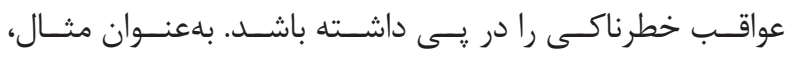

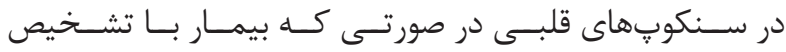

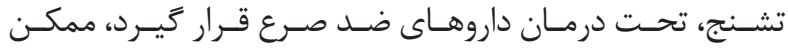

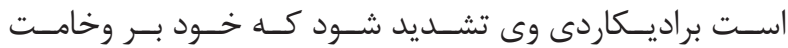

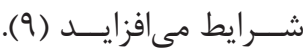

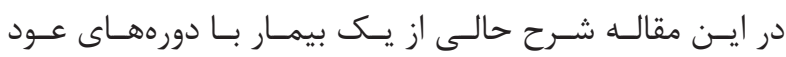

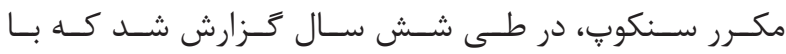

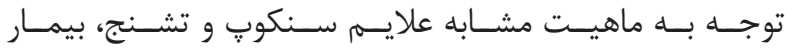

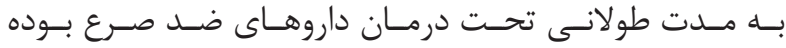

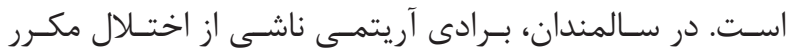

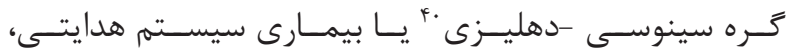

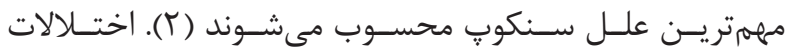

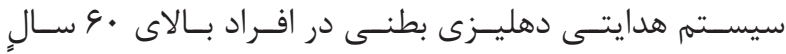

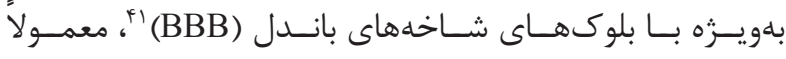

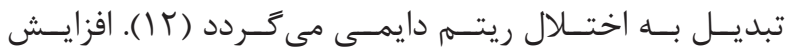

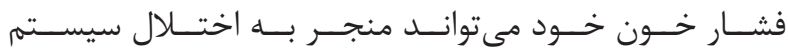

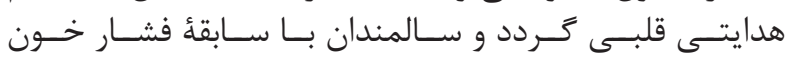

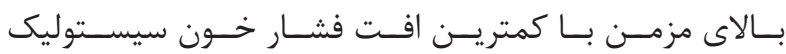

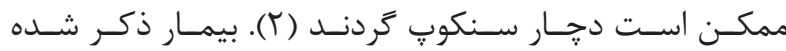

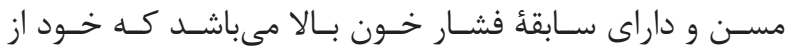

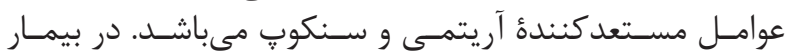

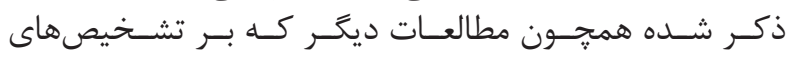

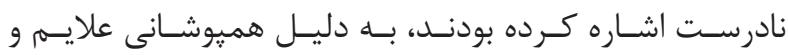

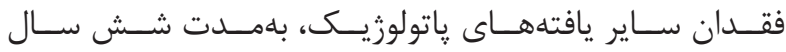

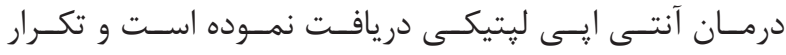

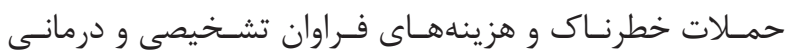

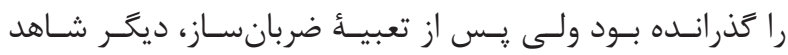

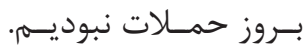

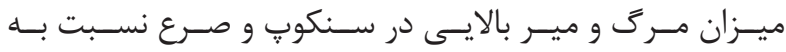

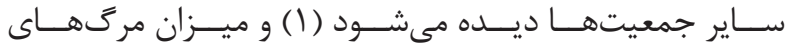

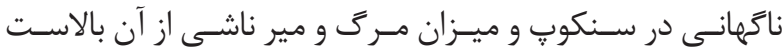

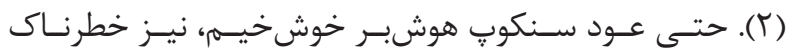

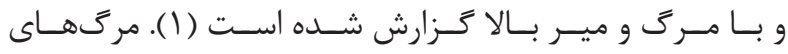

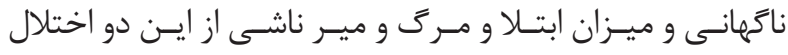

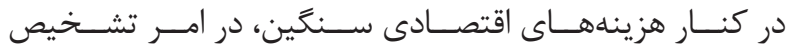

${ }^{37}$ Epigastric aura

${ }^{38}$ Mortality

${ }^{39}$ Morbidity

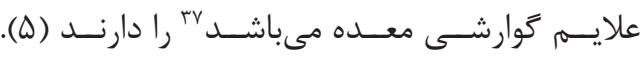

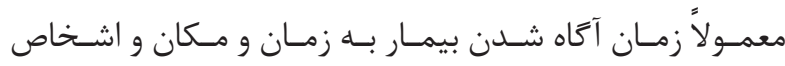

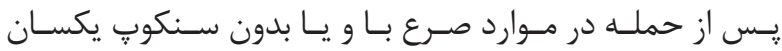

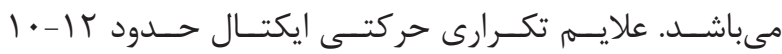

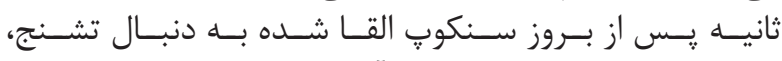

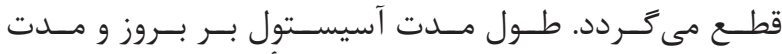

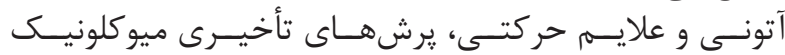

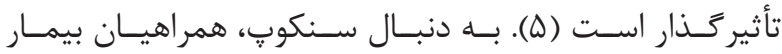

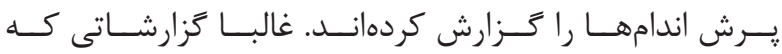
همراهيــان از ســــكو

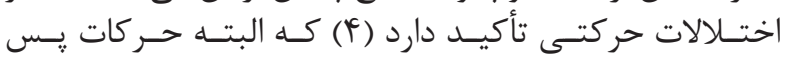

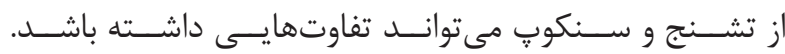

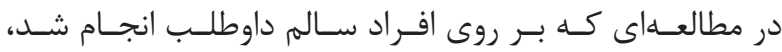

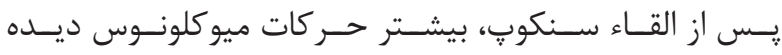

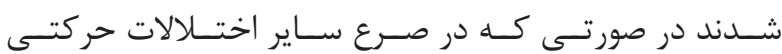

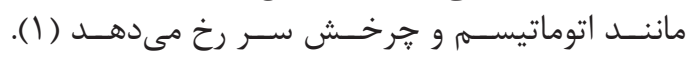

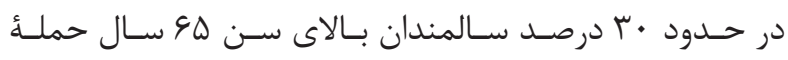

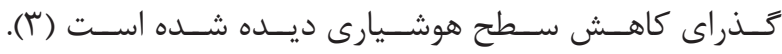
شــيوع ســنكو

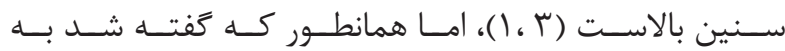

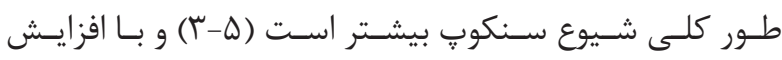

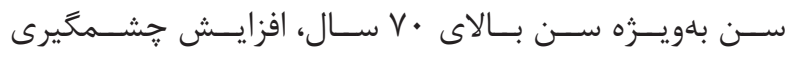

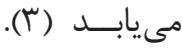

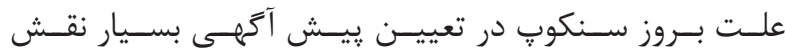

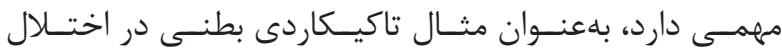

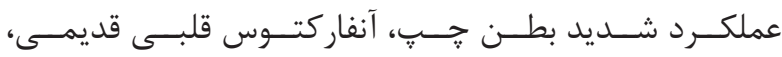

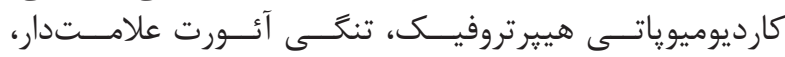

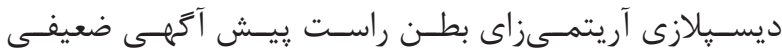

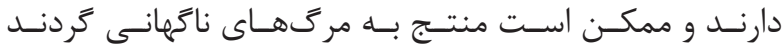

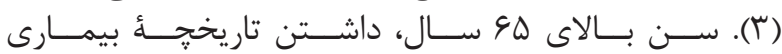

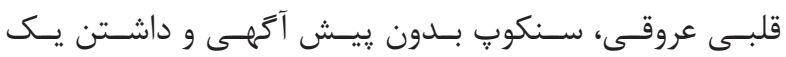

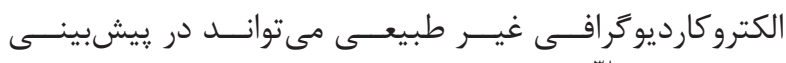

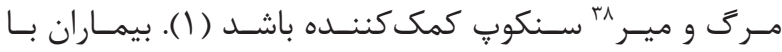

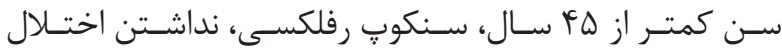

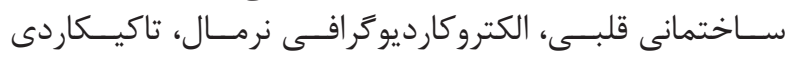

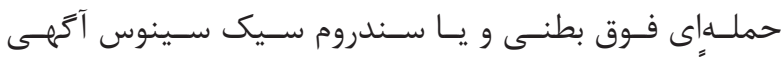

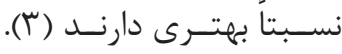

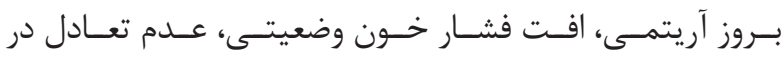

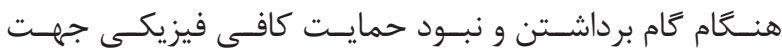

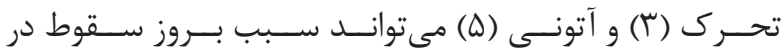

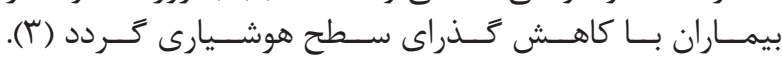

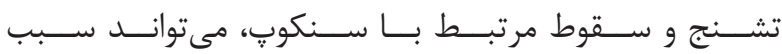

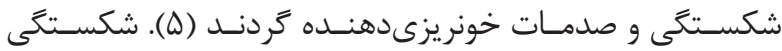

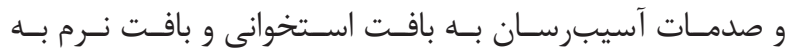




$$
\text { هزينههـــاى بيمـار مى تــــدد (1). }
$$$$
\text { تشكر و قدردانى }
$$

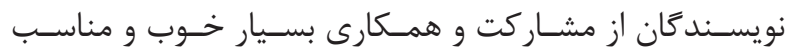

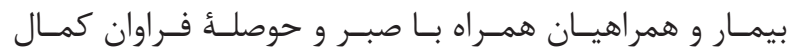

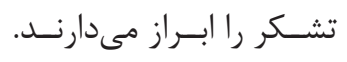

1. McKeon A, Vaughan C, Delanty N. Seizure versus syncope. Lancet Neurol. 2006; 5(2): 171-80.

2. Arthur W, Kaye GC. The pathophysiology of common causes of syncope. Postgrad Med J. 2000;76(902): 750-3.

3. Petkar S, Cooper P, Fitzpatrick AP. How to avoid a misdiagnosis in patients presenting with transient loss of consciousness. Postgrad Med J. 2006; 82(972): 630-41.

4. Sheldon R, Rose S, Ritchie D, Connolly SJ, Koshman ML, Lee MA, et al. Historical criteria that distinguish syncope from seizures. J Am Coll Cardiol. 2002; 40(1): $142-8$.

5. Duplyakov D, Golovina G, Lyukshina N, Surkova E, Elger CE, Surges R. Syncope, seizure-induced bradycardia and asystole: two cases and review of clinical and pathophysiological features. Seizure. 2014; 23(7): 506-11.

6. Zarraga IG, Ware DL. Syncope, seizure, or both? An unusual case of complete heart block. J Electrocardiol. 2007; 40(6): 493-5.

7. Sahin I, Karabulut A, Kızkapan F, Okuyan E. Epileptic seizures secondary to high degree atrioventricular block without escape rhythm. Turk Kardiyol Dern Ars. 2014; 42(7): 655-7.

8. Blanc JJ, Le Dauphin C. Syncope associated with documented paroxysmal atrioventricular block

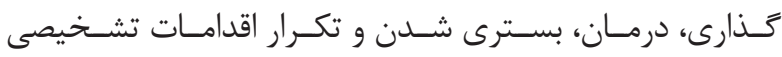

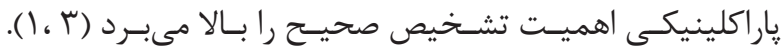

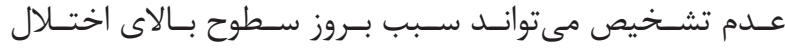

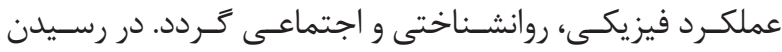

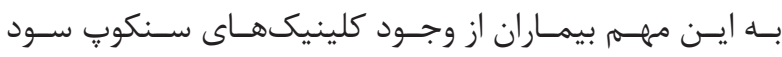

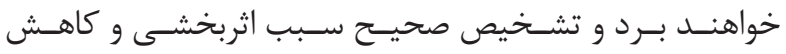

منابع

reproduced by adenosine 5 ' triphosphate injection. Europace. 2014; 16(6): 923-7.

9. Bergfeldt L. Differential diagnosis of cardiogenic syncope and seizure disorders. Heart. 2003; 89(3): 353-8.

10. El-Sherif N, Jalife J. Paroxysmal atrioventricular block: are phase 3 and phase 4 block mechanisms or misnomers? Heart Rhythm. 2009; 6(10): 1514-21.

11. Brignole M, Menozzi C, Bottoni N, Gianfranchi L, Lolli G, Oddone D, et al. Mechanisms of syncope caused by transient bradycardia and the diagnostic value of electrophysiologic testing and cardiovascular reflexivity maneuvers. Am J Cardiol. 1995; 76(4): 273-8.

12. Aste M, Brignole M. Syncope and paroxysmal atrioventricular block. J Arrhythm. 2017; 33(6): 562-7.

13. Lim Y, Singh D, Poh KK. High-grade atrioventricular block. Singapore Med J. 2018; 59(7): 346-50.

14. Seol SH, Kim DI, Park BM, Kim DK, Song PS, Kim $\mathrm{KH}$, et al. Complete Atrioventricular Block Presenting With Syncope Caused by Severe Hypothyroidism. Cardiol Res. 2012; 3(5): 239-41.

15. Allana SS, Ahmed HN, Shah K, Kelly AF. Ictal bradycardia and atrioventricular block: a cardiac manifestation of epilepsy. Oxf Med Case Reports. 2014; 2014(2): 33-5. 